\title{
Paulo Freire: gestão democrática em três formações
}

\section{Paulo Freire: democratic management in three formations Paulo Freire: gestión democrática en tres formaciones}

\author{
SONIA MARIA PORTELLA KRUPPA \\ https://orcid.org/0000-0001-6195-3436 \\ Universidade de São Paulo \\ Programa de Pós-graduação em Educação \\ Departamento de Administração e Economia da Educação \\ São Paulo, SP, Brasil \\ SILVIA ANDRADE DA SILVA TELLES \\ https://orcid.org/0000-0003-0413-8114 \\ Professora do Ensino Superior - aposentada \\ São Paulo, SP, Brasil \\ ALINE APARECIDA ANGELO \\ https://orcid.org/0000-0002-5926-8525 \\ Universidade Federal do Maranhão \\ Centro de Ciências, Educação e Linguagens \\ Bacabal, MA, Brasil
}

\begin{abstract}
Resumo: $\mathrm{O}$ artigo aborda três formações baseadas na gestão democrática de Paulo Freire, a partir da Educação Popular e da extensão universitária: o MOVA-SP, a Licenciatura em Educação do Campo e o Núcleo de Avaliação Institucional da FEUSP. A força e atualidade deste autor estão na gestão participativa, democrática e dialógica de diferentes coletivos em defesa de uma educação libertadora. São relatos que anunciam elementos para políticas alternativas e novas formas de organização da educação. São possibilidades contra hegemônicas a propostas conservadoras de conceber e fazer a gestão do trabalho pedagógico.
\end{abstract}

Palavras-chave: Educação, gestão democrática, diálogo, movimento social, transformação social.

Abstract: The article talks about three formations based on Paulo Freire's democratic management, from the Popular Education and university extension: MOVA-SP, the Degree in Field Education, and the Institutional Evaluation Center of FEUSP. The author's strength and timeliness are in the participatory, democratic, and dialogical management of different collectives in defense of liberating education. They are reports that announce elements for alternative policies and new forms of organization of education. These are possibilities contrary to the hegemony of conservative proposals to conceive and manage pedagogical work.

Keywords: education, democratic management, dialogue, social movements, social transformation. 
Resumen: El articulo aborda tres formaciones influenciadas en gestión democrática de Paulo Freire, basadas en la Educación Popular y la extensión universitaria: MOVA-SP, la Licenciatura en Educación Rural y el Centro de Evaluación Institucional de la FEUSP. La fuerza y actualidad de este autor está en la gestión participativa, democrática y dialógica de diferentes colectivos en defensa de una educación liberadora. Se trata de informes que anuncian elementos para politicas alternativas y nuevas formas de organizar la educación. Son posibilidades contrahegemónicas a las propuestas conservadoras de concebir y gestionar el trabajo pedagógico.

Palabras clave: Educación, gestión democrática, diálogo, movimiento social, transformación social.

\section{INTRODUÇÃO}

E se de repente..

For possível a esperança...

Este artigo traz a gestão democrática de Paulo Freire em três momentos de formações e de práticas.

O primeiro relata a proposta do MOVA-São Paulo, criação do próprio FREIRE, que se referencia nele em suas orientações e práticas, nas quais o vivido são expressão de seus conceitos principais: a gestão democrática, a educação como ato político, o saber popular, o diálogo e a democracia.

O relato que se segue traz marcada a inspiração freireana dos movimentos sociais do campo que, por força de sua luta, construíram a proposta das Licenciaturas em Educação do Campo.

Por fim, a trajetória do Núcleo de Avaliação Institucional da Faculdade de Educação da Universidade de São Paulo (NAI-FEUSP) que, partindo da concepção de extensão de Paulo Freire, estabelece canais de comunicação permanentes com uma rede de escolas públicas, situadas na grande São Paulo, fazendo com elas uma rede democrática de formação de futuros e de atuais docentes.

Desde o início dos anos de 1960, Paulo Freire trouxe a cultura popular para o fazer "revolucionário" de um processo educativo consciente e emancipatório. Os movimentos de cultura popular contribuíram para inserir, no âmbito da educação, a cultura como conceito, ideia, valor e fundamento para suas ações sociais e pedagógicas (BRANDÃO, 2010).

A educação implica uma relação que, para romper a realidade cultural opressora a que estão submetidos os educandos e fortalecer sua identidade cultural, deve ter o compromisso de compreender os anseios e os sonhos que estão presentes entre eles, buscando em conjunto as formas para alcançar este 
objetivo. Essa postura impõe aos homens e mulheres a necessidade de ser sujeito e não apenas espectador da história, implica em análise da realidade concreta e participação efetiva nos processos de mudanças.

Para Paulo Freire (1999), a educação, como formação humana, está baseada numa tríade de elementos fundamentais. Ela é simultaneamente política, ética e estética.

Não há educação sem opção política - a que se destina a educação? Resposta fundamental a ser dada numa sociedade marcada pela desigualdade como a brasileira.

A relação educacional deve ser ética, ou seja, é uma relação entre sujeitos - educandos e educadores - em que um lado da relação não pode ser submetido como objeto do outro, tal como é a prática da educação bancária criticada por Freire. Daí a importância do diálogo democrático como método e conteúdo formador, posto que essencial para a formação permanente e incessante dos valores humanos, que devem permear a relação entre educandos e educadores, fortalecendo a aprendizagem da escuta entre ambos.

A educação é estética: há uma belezura do fazer educacional como ato coletivo que busca a decência do ser humano (FREIRE, 1999).

Nesse sentido, a educação é uma experiência criadora. O educando é sujeito que cria o seu próprio aprendizado - aprende a razão de ser do objeto/ tema/conteúdo a ser aprendido. Para Paulo Freire aprender não é ser teleguiado. A curiosidade é própria do ser humano e essa curiosidade precisa ser estimulada.

A favor da espontaneidade e não do espontaneísmo, Paulo Freire sempre foi contrário aos pacotes de conteúdos: apostava na capacidade dos seres humanos de criarem sua própria maneira de aprendizagem, uma aposta gnosiológica na autonomia do sujeito que aprende, o que exige a organização pelos professores de formas que possibilitem e fomentem essa autonomia.

Prática de ensinante e de aprendente - clima de alegria - mas que preserva a relação ética a cada instante como fundante da relação humana com o outro: nem calar, nem usar o outro para "domesticá-lo"- o sentido profundo da democracia formadora de consensos sem temor das ideias divergentes e do debate.

Esperança na existência humana, a esperança que faz parte da natureza humana, constituída social e historicamente - a inconclusão humana é uma característica do humano - somos capazes de nos reconhecermos como inacabados - termos consciência do processo histórico - educação como processo de procura. Procurar não é possível sem esperança (pedagogia da esperança). Brigar pela esperança tem razão ontológica! 
Paulo Freire refuta a experiência pragmática de treinar o educando e o educador. É contra as influências tecnológicas que podem amaciar as vontades e a curiosidade. Nesse sentido propõe uma rebelião contra a ética que só cuida do lucro, do ensino a distância e das avaliações externas de controle.

Nas três formações os ensinamentos freireanos estão presentes. Diálogo, democracia, participação e esperança são elementos comuns das três formações relatadas.

\section{MOVA - SÃO PAULO: A OUSADIA DE FREIRE NA ADMINISTRAÇÃO PÚBLICA MUNICIPAL}

Paulo Freire afirma a importância transformadora que o saber popular pode ter e de forma coerente a participação popular foi uma das grandes marcas do Movimento de Alfabetização de Jovens e Adultos da Cidade de São Paulo MOVA SP, criado em 1989, quando a prefeita Luiza Erundina e o Prof. Paulo Freire, enquanto Secretário da Educação, assumem o governo da cidade de São Paulo que, à época, tinha cerca de 1 milhão de pessoas analfabetas, com mais de 15 anos de idade e, em torno de 2,5 milhões de pessoas que possuíam menos de 4 anos de escolaridade.

O Mova não constituiu uma ação isolada. Deve ser analisado num contexto mais amplo da atuação da Secretaria Municipal de Educação-SP, pois, juntamente com o programa de Educação de Jovens e Adultos - EDA ${ }^{1}$ e o Programa de Alfabetização de Funcionários, fez parte de uma dentre as quatro prioridades básicas que nortearam a ação política deste governo².

Essa era a primeira vez que um governo da cidade de São Paulo colocava em suas diretrizes políticas de educação uma preocupação explícita com Educação de Jovens e Adultos, traduzindo-se em projetos efetivamente concretizados.

$\mathrm{Na}$ cidade de São Paulo, vários movimentos populares que ingressaram no MOVA vinham de uma longa trajetória de lutas por direito à moradia, à educação, à saúde e ao transporte ${ }^{3}$. Esses movimentos foram se constituindo em movimentos de educação, na medida em que se mobilizavam por aumento

1 EDA - Programa de Educação de Adultos, correspondente ao ensino da $1^{\mathrm{a}}$ à $4^{\mathrm{a}}$ série do Ensino Fundamental I, na modalidade de ensino supletivo, sob responsabilidade da Secretaria de Bem Estar Social.

2 As quatro prioridades que nortearam as políticas da Secretaria Municipal de Educação- SME, durante a gestão Luiza Erundina foram: "Democratização ao Acesso"; "Nova Qualidade de Ensino”; "Democratização da Gestão" e "Educação de Jovens e Adultos"

3 Dados extraídos dos históricos apresentados nos projetos que os movimentos populares apresentavam à Secretaria de Educação ao ingressar no MOVA (1989). 
de vagas nas escolas, melhoria na qualidade da educação, segurança nas escolas, contra taxas abusivas cobradas pelas Associações de Pais e Mestres das escolas e criação de cursos supletivos.

Nesse contexto, os movimentos populares, inspirados na concepção de educação freireana e nas experiências de educação de adultos dos anos de 1960, progressivamente foram avaliando a necessidade deles mesmo alfabetizarem os jovens e adultos dada a importância que o processo de alfabetização representa para o fortalecimento das lutas dos movimentos populares.

Para Freire, "o trabalho de alfabetização, na medida em que possibilita uma leitura crítica da realidade, se constitui como um importante instrumento de resgate da cidadania e reforça o engajamento do cidadão nos movimentos sociais que lutam pela melhora da qualidade de vida e pela transformação social". (FREIRE, 1994, p. 126)

No final dos anos de 1988, quando já tínhamos nas mãos o resultado das eleições e o convite a Paulo Freire para ser Secretário da Educação, os movimentos começaram a se reunir para pensar um projeto que contasse com a sua participação, assim como, por parte da Secretaria da Educação, discutia-se um projeto em parceria com os Movimentos Populares: um projeto de gestão participativa e democrática.

A parceria, Secretaria Municipal de Educação-SME e Movimentos Populares, estratégia básica na construção do MOVA-SP, foi intencionalmente criada com a finalidade de se garantir a participação popular, num reconhecimento do saber acumulado pelos movimentos populares já engajados nesta luta e a importante contribuição que estes tinham a dar na construção deste trabalho, compreendendo a força transformadora que a educação popular pode imprimir em um projeto de educação de jovens e adultos. (MOVA-SP, Caderno n ${ }^{1}$, 1989).

Nesta parceria, foi de responsabilidade da Secretaria Municipal de Educação- SME apoiar financeira e materialmente os projetos de Alfabetização de Jovens e Adultos, desenvolvidos pelos movimentos populares; criar novos núcleos de alfabetização nas áreas onde os movimentos ainda não assumiam esta tarefa; e garantir a orientação político-pedagógica e a formação permanente dos educadores populares. (MOVA-SP, Caderno n 1, 1989). À vista disso, cabe explicitar que os princípios norteadores do programa não previam de forma alguma a desobrigação do Estado para com o processo de escolarização da população e/ou o barateamento de custo da Educação de Jovens e Adultos na cidade, na conhecida lógica de que aos pobres qualquer educação serve. A estratégia de um trabalho em parceria que garantisse a participação popular, como 
persistia Paulo Freire, significa o reconhecimento à contribuição que a educação popular tem a dar em um processo de alfabetização que assegure aos jovens e adultos o direito a uma educação comprometida com uma

Para a concretização da participação dos movimentos populares e efetivação da parceria SME e Movimentos Populares, foi criado o Fórum Municipal de Alfabetização, que inicialmente definiu as diretrizes e princípios político-pedagógicos do processo de alfabetização, estabelecendo e organizando sua estrutura de trabalho. Nesse espaço, se deu a elaboração da Carta de Princípios do programa.

Coletivamente, lideranças e educadores dos movimentos populares, educadores da Secretaria de Educação participaram das discussões, da elaboração e da execução do programa MOVA-SP e, desta maneira, o grupo foi tecendo o Projeto Político Pedagógico baseado na carta de princípios.

Em relação à proposta inicial do programa, é importante destacar que desde as primeiras reuniões do MOVA, Freire afirmava a importância de se contemplar não só a alfabetização, mas sim a alfabetização e a pós-alfabetização. Em especial, seus argumentos pedagógicos eram muito coerentes com as "políticas de ciclos" debatidas em SME. Na prática, os projetos pedagógicos elaborados pelos movimentos e discutidos nas reuniões de formação permanente já eram planejados considerando um trabalho voltado à alfabetização e à pósalfabetização. $^{4}$

Pode-se afirmar que os principais pilares do MOVA, para que de fato acontecesse a participação popular e coletivamente se construísse o programa, foram a criação dos fóruns, a elaboração da carta de princípios do programa e os espaços de formação.

Para participar do MOVA-SP “a entidade deveria ter representação no Fórum dos Movimentos Populares de Alfabetização de Adultos da Cidade de São Paulo"; precisava já desenvolver, ou pretender iniciar trabalhos de alfabetização e pós-alfabetização com grupos populares, sem fins lucrativos; desenvolver seus trabalhos dentro da concepção político-pedagógica libertadora; indicar os monitores que tivessem o domínio da leitura e da escrita e se comprometessem a participar do processo de formação permanente junto ao coletivo dos educadores do projeto MOVA-SP (MOVA-SP, Caderno n 1, 1989).

\footnotetext{
4 Conforme a Publicação "Construindo o Ciclo Ensino Fundamental I", até setembro de 1971, os trabalhos do programa se restringiam oficialmente à alfabetização, embora vários movimentos já desenvolvessem a pós-alfabetização. Diante da necessidade de adequar o programa a essa realidade e de questões objetivas, como a expedição de atestado para possibilitar o ingresso dos alunos na $5^{\text {a }}$ série do ensino regular ou na suplência II, foi desenvolvido um amplo processo de debate entre os Movimentos e a SME que culminou no projeto do Ensino Fundamental I (Construindo o Ciclo Ensino Fundamental I, 1992, p. 4)
} 
Estes critérios, registrados em um projeto, eram analisados e discutidos, primeiramente pelos movimentos da região e, após aprovação, o projeto era encaminhado para parecer técnico da Secretaria de Educação. Não se tratava de uma triagem ideológica, nem tão pouco enquadramento pedagógico, mas sim uma forma de se garantir uma gestão democrática em que todos os participantes pudessem verificar o envolvimento da entidade com a comunidade e seu real interesse e compromisso com os objetivos do programa. Paulo Freire insistia que era fundamental o trabalho ser construído coletivamente, seus sujeitos terem clareza de sua direção, porém sem perder a autonomia dos movimentos.

Também era no espaço do fórum que se discutia o apoio financeiro e material aos movimentos populares, prevendo-se, por exemplo, o pagamento da ajuda de custo aos educadores, a verba necessária para o custeio da infraestrutura da sala de aula e do material pedagógico. Nessa discussão estava posta a responsabilidade de todos os participantes do projeto com a utilização da verba pública. A Secretaria de Educação não poderia se tornar mera repassadora de verbas. Essa responsabilidade era de todos: um projeto gestado coletivamente.

Assim, os fóruns tornaram-se um espaço democrático de discussão, construção e deliberação de questões de gestão, estrutura, financiamento, administrativas e pedagógicas. Positivamente, os fóruns se tornaram um espaço privilegiado de formação de todos: educadores dos movimentos populares e da Secretaria de Educação.

A carta de princípios definiu a direção política e pedagógica do trabalho a ser realizado, marcando o processo democrático do MOVA. Durante sua feitura, Paulo Freire debateu largamente sua concepção de alfabetização desde suas primeiras experiências em alfabetização de adultos. Insistia constantemente para que não copiássemos essas experiências anteriores. Dizia ele: o momento é outro, o contexto sociopolítico é outro.

Uma mesma compreensão da prática educativa e uma mesma metodologia de trabalho não operam necessariamente de forma idêntica em contextos diferentes. A intervenção é histórica, é cultural, é política (...) as experiências não podem ser transplantadas, mas sim reinventadas. (FREIRE, 1988, p. 8)

Uma educação, baseada nas concepções freireanas de educação, não poderia trazer "pacotinhos pedagógicos"; impossível se ter um currículo único para todos. Isso significaria engessar a realidade existente em cada sala de aula, significaria não respeitar os saberes dos educandos e dos educadores, assim como negaria a possibilidade da necessária reflexão crítica sobre a prática educativa. Daí a elaboração de princípios que assegurassem a concepção político-pedagógica do 
MOVA, resguardando aos movimentos a liberdade de adequarem as propostas à realidade específica de cada entidade e, assim, respeitar a autonomia dos movimentos populares. (FREIRE, 1999)

Em vários momentos de conflitos, dúvidas, discordâncias, inclusive metodológicas, recorreu-se aos princípios do programa para que juntos, no Fórum Mova, pudéssemos encontrar saídas para as nossas inquietações, nossos problemas. Ela não só alicerçou a concepção político-pedagógica do programa como apontou os caminhos para se realizar o processo de formação permanente dos educadores; estabeleceu que a elaboração conjunta, secretaria e movimentos, seria o guia do programa 5 .

Trabalhar em parceria, aprender como se constrói coletivamente o trabalho, era sempre pauta de discussões e campo de muitas divergências entre nós, Movimentos e Secretaria da Educação, e, também internamente, por ambos os lados. Foi nesse processo de confrontos de ideias, estudando, refletindo nossa prática educativa, tanto da sala de aula, como a dos espaços de formação permanente entre educadores dos movimentos populares e educadores da Secretaria da Educação que fomos descobrindo como desenvolver o trabalho em parceria, ou seja, o que era realmente "fazer juntos". Como sempre nos afirmou Paulo Freire, "não é fazer para eles e nem fazer por eles, mas é fazer com eles". (FREIRE, 1987).

A elaboração conjunta foi um dos grandes desafios do programa. Esse foi um dos grandes legados que Paulo Freire nos deixou. Ele nos instigou a aprender a trabalhar coletivamente. Ele não trouxe fórmulas, nem tão pouco nos apontou o caminho certo, mas nos ensinou o que é o diálogo, o que é na prática o que tanto lemos sobre dialogicidade no livro Pedagogia do Oprimido.

Pode-se afirmar que dúvidas, diferenças, divergências e conflitos, em uma relação muitas vezes tensa e tumultuada, mas muitíssimo educativa, foram características que permearam todo o caminho percorrido. Nela, comprovamos o que Paulo Freire sempre acreditou: é possível concretizar um trabalho voltado a ampliar a cidadania, de forma democrática, participativa e coletiva.

\section{FREIRE E A LICENCIATURA EM EDUCAÇÃO DO CAMPO}

As bases epistemológicas das Políticas Públicas de Expansão para a Educação Superior do Campo foram alimentadas pelos fundamentos da Educação Popular (MARTINS e JEZINE, 2018). A apreensão da realidade concreta, a 
participação popular democrática, a relação teoria e prática (práxis), a formação para emancipação sob os princípios da ética e da igualdade são categorias constituintes do paradigma do Movimento da Educação do Campo, em fecunda conexão com os princípios da Educação Popular.

Ao final dos anos de 1990, esse Movimento surge por meio da mobilização por direito à terra e por outros direitos, entre eles o da educação. Embora sua origem esteja neste período, os referenciais que fundamentam as diferentes práticas educativas da Educação do Campo têm suas raízes e aprendizagens na educação popular.

A trajetória histórica da educação popular foi construindo uma teoria de formação humana do sujeito e uma práxis coletiva que forma subjetividades dialogantes, críticas e capazes de construir outras relações sociais e uma concepção de educação questionadora sobre as finalidades do processo educativo e dos conteúdos presentes nos processos educativos para os povos do campo. Esse repertório de conhecimentos e práticas foi resgatado e sistematizado pelos movimentos sociais atuais, especialmente pela Educação do Campo (SILVA, 2006).

A institucionalização das Licenciaturas em Educação do Campo (LECs) no Brasil é conquista do Movimento, viabilizada pelo Programa Nacional de Educação do Campo (PRONACAMPO), considerando experiências anteriores de formação, desenvolvidas pelo Programa Nacional de Educação na Reforma Agrária (Pronera) e Programa de Apoio à Formação Superior em Licenciatura em Educação do Campo (Procampo). Por meio dessas licenciaturas, a formação profissional do educador do campo apresenta-se num formato diferenciado das convencionais já existentes.

O curso objetiva preparar seus participantes para a atuação na educação básica nos anos finais do Ensino Fundamental, no Ensino Médio e na combinação com a Educação Profissional; e para a gestão de processos educativos escolares e comunitários. Os tempos e espaços de formação são organizados pelo regime da Alternância entre Tempo Universidade e Tempo Comunidade, visando à articulação entre conhecimento teórico e a realidade concreta destes territórios de saberes. A formação multidisciplinar é outra característica do curso, tão promissora quanto desafiadora, na medida em que implica conferir terminalidade ao curso por área de conhecimento ${ }^{6}$ para a atuação na docência.

Os caminhos trilhados para a constituição dessa política de formação de educadores envolveram diversos seminários, conferências; debates em torno da formulação de diretrizes, pareceres e programas de formação, que pudessem

6 As possíveis áreas de conhecimento são: linguagens e códigos; ciências humanas; ciências da natureza; matemática; ciências agrárias. 
viabilizar a presença da concepção de Educação do Campo nas políticas públicas de escolas do campo e de ensino superior. Destacam-se: as Conferências Nacionais de Educação do Campo (CNEC), realizadas em 1998 e em 2004; o Pronera, 1998 (Portaria n. 10/1998 do Ministério Extraordinário da Política Fundiária); as Diretrizes Operacionais para a Educação Básica nas Escolas do Campo" (Parecer no 36/2001 e Resolução 1/2002 do Conselho Nacional de Educação); e do PRONACAMPO, instituído pelo Decreto n. 7352/2010.

Na declaração divulgada após a II CNEC, o Movimento afirmou sua trajetória enraizada na Educação Popular (Paulo Freire) e nas lutas sociais da classe trabalhadora do Campo. Essa trajetória pode ser observada na gestão política e pedagógica em que se constituiu as LECs, pautadas no diálogo entre os movimentos, na participação, na análise da realidade concreta, na cultura e na estética de um fazer educativo, objetivando a transformação da situação de exclusão em que se encontram frente ao uso social da terra e a outros direitos.

Esse processo não se deu sem divergências. Por exemplo, na elaboração do Pronacampo foi dado um espaço menor para os movimentos sociais nos grupos de trabalho que o elaboraram. Houve a entrada do agronegócio, disputando os fundos públicos, o que pode ser percebido pela incorporação no Pronacampo, na concepção de formação profissional, com o modelo hegemônico da agricultura industrial representado pelo Pronatec $\mathrm{Campo}^{7}$; e pela proposta de oferta de formação inicial a distância para os educadores do campo ${ }^{8}$. Ainda assim, o Movimento soube aproveitar as brechas dessa proposta e por meio dele fez-se a institucionalização das LECs no Brasil.

É certo afirmarmos que todas as conquistas na Educação do Campo foram marcadas pela participação ativa dos movimentos sociais do campo, seja na construção ou na crítica daquelas que destoam de seus preceitos. O FONEC tem se tornado espaço de resistência e diálogo do movimento para o debate acerca das políticas públicas para escolas e o ensino superior.

As mobilizações da Educação do Campo referenciam-se na concepção de gestão democrática, pois os movimentos sociais lutam para serem partícipes e protagonistas das políticas públicas das quais se beneficiam, assim como por uma educação de abordagem crítica e antiautoritária, tal como nos ensinou Freire.

7 Programa Nacional de Acesso ao Ensino Técnico e Emprego.

8 Segue trecho da carta elaborada no Fórum Nacional de Educação do Campo (FONEC) em que se expressam as referidas críticas: "O Movimento de Educação do Campo tem problematizado a formação de educadores à distância, pela compreensão de que as diferentes dimensões da formação profissional necessária ao projeto educativo dos trabalhadores não têm como se realizar de forma plena nessa modalidade." (FONEC, 2012). 
Por isso, a participação é uma marca desse movimento e, conforme Freire, faz parte da nossa vocação ontológica de intervenção no mundo, cujo sentido é:

(...) não poder ser reduzida a uma pura colaboração que setores populacionais devessem e pudessem dar à administração pública. [...] Implica, por parte das classes populares, um “estar presente na História e não simplesmente nela estar representadas". Implica a participação política das classes populares através de suas representações ao nível das opções, das decisões e não só do fazer o já programado[...] (FREIRE, 1994, p. 75)

Construir política pública para uma educação transformadora exige análise do conjunto da realidade em que nos inserimos. A análise concreta da realidade é fundamento para uma participação ativa e emancipadora, na medida em que homens e mulheres percebem o mundo e nele agem.

Entendemos que, na política e nos currículos de formação das LECs, há fecundas raízes da educação popular de inspiração freireana. Discorremos sobre elas a partir de três eixos:

a) $\mathrm{Na}$ análise da realidade concreta, a práxis.

Essa prática se expressa na apreensão do campo em sua diversidade, contradições, culturas e potencialidades. Compreende-se que a transformação da sociedade no campo inicia-se com a Reforma Agrária popular, combinada com a agricultura camponesa e a agroecologia. Essa transformação faz parte de uma totalidade de outras necessárias para a emancipação da classe trabalhadora, combinada com a superação do capitalismo.

Nas LECs, a organização do currículo no regime de Alternância traz a comunidade como espaço formativo num aspecto físico, político, social e cultural. A alternância abre como possibilidades a construção de mediações pedagógicas fundamentais para integrar tempos e espaços de formação, processos metodológicos e epistemológicos na construção do conhecimento entre sujeitos e instituições envolvidas (BEGNAMI, 2019, p. 273).

Ao educador do campo, ter na realidade concreta a base necessária para a produção do conhecimento permite a prática social como ponto de partida e de chegada, "ressaltando os seus princípios de emancipação humana, participação popular, amorosidade, solidariedade, conhecimento crítico, transformação da realidade, saberes, justiça política, econômica e socioambiental" (MARTINS e JEZINE, 2018, p. 170).

b) A gestão democrática como princípio do curso.

A participação popular está presente desde a elaboração desta política de formação com a pretensão de instituir entre os participantes uma cultura de luta por direitos e de trabalho coletivo. Por isso, a relevância de serem criados espaços 
de gestão democrática, tais como: a organicidade no curso, que estimule o trabalho coletivo entre docentes, a auto-organização dos estudantes, o envolvimento com movimentos sociais.

A formação de educadores do campo envolve não somente a competência técnica para a docência, mas também o engajamento na luta pela transformação social, o que requer desencadear e gerir democraticamente processos educativos escolares e comunitários transformadores. O Movimento da Educação do Campo espera formar educadores que possam discutir, ter voz (ganhando-a) na construção de políticas para as escolas do campo, na luta contra seu fechamento e na disputa de seu currículo, para uma proposta progressista em oposição aos preceitos da escola capitalista?.

c) Na educação libertadora, a estética, a amorosidade e a esperança.

Os movimentos sociais do campo desafiam estes espaços institucionais em sua forma: a forma escolar e a forma universidade. A educação transformadora deve construir outras pedagogias a partir destes outros sujeitos.

No caso das LECs, os movimentos sociais trazem a boniteza das místicas, da organização dos estudantes, da instituição da comunidade como espaço de formação. É certo que, em cada universidade, o peso dessas práticas varia; elas possuem características próprias, que não cabe aqui uma análise precisa dessas especificidades.

A mística, por exemplo, é uma prática comum na história dos movimentos sociais, que têm sua origem entrelaçada à religiosidade das populações camponesas. No entanto, a mística ultrapassa o espectro do sagrado entrelaçando a vida social e a luta política, buscando a aproximação do fazer do presente com a utopia do futuro (BOGO, 2012). Com as místicas, a arte, a música, a poesia, o teatro e a militância se estreitam em uma manifestação que é única e esperançosa. Estão presentes nas escolas do campo do $\mathrm{MST}^{10}$, nas Escolas Famílias Agrícolas e na universidade, por meio das LECs e de outros cursos oriundos do Pronera.

Nos espaços da escola, da universidade se (re)constroem experiências e sentidos pedagógicos, abrindo possibilidades para novas práticas sociais, desfazendo-se de referências cristalizadas, na medida em que nos entendemos como sujeitos em uma sociedade em transição.

A práxis criativa e estética, ao disputar espaços enrijecidos, afirma a amorosidade e a esperança como exigências do fazer pedagógico, como antecipação de uma promessa que já começou a ser cumprida.

9 Essa oposição à escola capitalista sustenta-se na crítica às políticas públicas de caráter neoliberal, notadamente representadas pelas reformas empresariais de educação, que estão em processo de implementação no Brasil (FREITAS, 2018).

10 Movimentos dos Trabalhadores Rurais Sem Terra.

706 - Rev. Bras. Polít. Adm. Educ. - v. 37, n. 2, p. 695 - 715, mai./ago. 2021 
Entendemos, que o desenvolvimento das LECs deve estar atento aos princípios desse Movimento, cuidando para que os cursos não se afastem dessa historicidade. Esse é um desafio posto ao processo de institucionalização desse curso nas universidades brasileiras. Por isso, é relevante a continuidade dos espaços construídos pela Educação do Campo para a discussão das LECs, como o FONEC, os eventos nacionais de formação de formadores ${ }^{11}$, e os Seminários Nacionais da Licenciatura em Educação do Campo ${ }^{12}$.

\section{NÚCLEO DE AVALIAÇÃO INSTITUCIONAL DA FACULDADE DE EDUCAÇÃO DA USP (NAI-FEUSP) - UMA FORMAÇÃO REFLEXIVA E APRENDENTE}

Paulo Freire está presente na forma e no conteúdo do Núcleo de Avaliação Institucional da Faculdade de Educação da USP (NAI-FEUSP) - conceitos de diálogo/extensão, gestão democrática, educação popular e história.

Em seu trajeto e em sentido oposto da direção instituinte das formações desenvolvidas pelo MOVA-SP e pelas Licenciaturas do Campo - temporalmente próximas do movimento social que lhes garante a história - o NAI-FEUSP parte do instituído e do regrado: a Universidade e a Escola Pública de Educação Básica, portadoras de relações disciplinares e ordenadas. Faz assim uma trajetória que pretende recuperar a $\mathrm{VOz}$ instituinte do movimento social e da comunidade: a história e suas temporalidades, a realidade social complexa na qual vivem os sujeitos sociais, constituindo o território onde se localizam e buscando outro modo de relações formativas.

O Núcleo de Avaliação tem forte atividade extensionista junto à rede de escolas públicas, organizada ao longo de sua trajetória, iniciada em Curso, ocorrido durante o I Seminário Internacional de Avaliação Educacional na Faculdade de Educação da USP, em agosto de 2013, como parte de um Projeto de Pesquisa Internacional "Avaliação e Políticas Públicas de Educação Básica: um estudo em escolas de São Paulo e Porto", que, em 2011, envolveu professores das Faculdades de Educação da USP e da Universidade Estadual de Campinas (UNICAMP), no Brasil, e da Faculdade de Psicologia e de Ciências das Educação da Universidade de Porto, em Portugal. Este projeto teve como centro o estudo crítico das avaliações externas e de suas consequências nas práticas escolares, apresentando o contraponto da avaliação institucional, negociada e democrática, que propõe a autonomia de cada escola na elaboração de projeto político pedagógico próprio,

\footnotetext{
11 Seminários Nacionais de Formação Continuada de Professores da Licenciatura em Educação do Campo. Foram três encontros realizados entre 2017 e 2018. 
orientador de processos de autoavaliação e de busca permanente da melhoria da qualidade da educação oferecida (TERRASECA, 2006; MENDES et al., 2015). Coerente com os princípios e com a forma como concebe sua atuação, a contribuição de Paulo Freire é incisiva na maneira pela qual se constituem as atividades de extensão do Núcleo frente aos dois outros eixos da tríade acadêmica: o ensino e a pesquisa.

O Núcleo, não se pautando pela extensão de conhecimentos às escolas e sim pelo diálogo, afirma "o que fazer educativo libertador" como uma relação entre escola e universidade (FREIRE, 1983, p.14). Confirma a condição de sujeito a cada uma das partes em relação, negando, com o autor, que conhecer seja o ato por meio do qual um sujeito transformado em objeto recebe dócil e passivamente os conteúdos que o outro lhe dá ou lhe impõe - "conhecer é tarefa de sujeitos, não de objetos" (FREIRE, 1983, p. 18) - organizando-se numa rede de formação em expansão permanente. Constitui, dessa maneira, um plano de atividades em constante aprimoramento, que inclui os estágios de diferentes cursos de licenciatura e outras modalidades de formação continuada, abertas aos profissionais das escolas, envolvendo a definição partilhada dos conteúdos e das metodologias. Para isso, o NAI-FEUSP vale-se das reuniões ordinárias quinzenais ou mensais. Dos registros sistematizados dessas reuniões emergem os temas da formação e outras ações a serem desencadeadas (debates, manifestos, cartas públicas, etc.) e, dessa forma, em espiral, avaliar se transforma em/na criação de outros dispositivos formadores. Para o Núcleo, avaliar é produção de sentido e de criação de ação futura (ARDOINO e BERGER, 1986).

Faz parte desse Plano a integração entre as ações de formação inicial/ estágios, de formação continuada (cursos e palestras) com as demais ações de sala de aula, no interior da universidade: em algumas disciplinas, os profissionais das escolas participam na condição de alunos especiais.

Considerando que todos os integrantes devem assumir uma postura investigativa, o Núcleo estimula atividades de pesquisa em torno de hipóteses elaboradas em sua trajetória, tais como: (1) os resultados na escola das avaliações externas, no que diz respeito a melhoria efetiva da qualidade, são pouco consistentes quando comparados ao que resultam de processos de auto avaliação e de avaliação institucional, que fortalecem projetos políticos pedagógicos, relacionados a situações das comunidades escolares e a seus território; (2) a afirmação da diferença entre as escolas é decorrente da constatação de configurações profissionais e territoriais distintas; (3) a definição da escola - necessariamente, ela é o que são os seus protagonistas: estudantes profissionais e demais membros da comunidade - significa dizer que a escola reflete a mobilização da comunidade escolar no território; (4) hipótese decorrente: produzir a mobilização da comunidade é uma 
ação virtuosa, que amplia a qualidade do projeto político pedagógico, ou, dito de outra forma: se a escola tiver consciência de sua condição de sujeito coletivo e, especialmente, se a sua atuação for baseada na gestão democrática, a qualidade social de sua atuação será ampliada; (5) ainda decorrente de 3: o surgimento de uma escola pública é fruto de reivindicação popular nem sempre registrada; (6) a escola tem condições de articular uma rede de políticas públicas no território, em especial, quando ela se relaciona com outros equipamentos públicos da educação, fortalecendo canais de diálogo com os domicílios. Em decorrência se a escola superar a fragmentação das faixas etárias em seu diálogo com as famílias, tomando-as enquanto "totalidades" - os domićlíos como sujeitos de direitos - a qualidade dos serviços educacionais oferecido pelas escolas articuladas é maior; (7) processos de autonomia e de adensamento da compreensão do vivido territorial produzem qualidade e currículos diferenciados; (8) a escola que considera o conhecimento popular e o conhecimento sistematizado tem atuação maior que os limites físicos do prédio que a abriga - essa dimensão se amplia quanto mais a escola se relaciona com seu território - conceitos como área de abrangência e área de influência, usualmente tomados pelas políticas públicas de saúde na definição dos currículos das unidades básicas, são importantes de serem compreendidos e utilizados pelas escolas; (9) uma escola efetivamente ensina e aprende com outra escola e, portanto, é profundamente formador a gestão democrática dos encontros entre escolas; e, por fim, (10) a universidade é frágil na formação docente quando ela se mantém dentro de seus limites físicos, sem considerar que a formação de futuros professores é feita em relação: uma parte pode ocorrer dentro da universidade e outra deve ser em parceria com escolas públicas, no conjunto de suas atividades, sendo determinante a criação de novas estruturas de relacionamento, novas estratégias e dispositivos, originando novos complexos formativos.

Ao incentivar a reflexão sobre o conjunto desses itens, o NAI-FEUSP busca realizar-se sob a expressão profundamente democrática de: avaliar com todos para mudar a escola. 


\section{Figura 1 - Mapa Conceitual do percurso formativo democrático do NAI-FEUSP.}

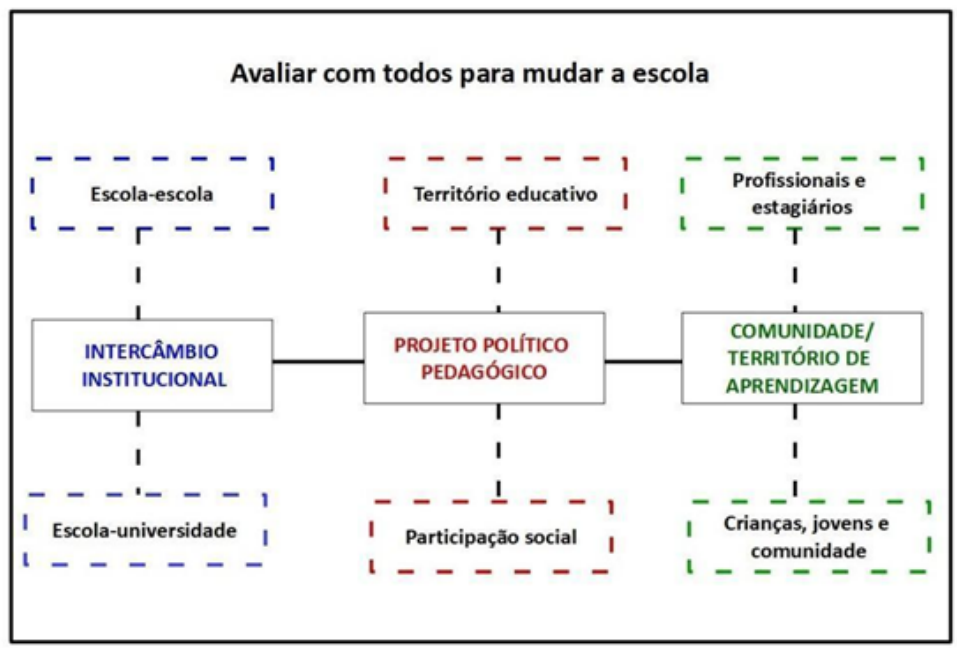

Fonte: NAI-FEUSP.

O Núcleo mantém "porta aberta” às escolas públicas, em geral, trazidas por aquelas que já se encontram inseridas em suas atividades e a quem são apresentados seus princípios orientadores: a defesa da escola pública e de sua autonomia e identidade, a construção democrática de seu currículo, o destaque para a perspectiva de transformação social do território onde a escola se localiza. O que envolve ações matriciais com outras políticas públicas (saúde, assistência social, cultura, lazer e esporte) e com os movimentos e organizações sociais.

Escolas e Universidade são sujeitos aprendentes e ensinantes, com possibilidade criadora que deve ser ampliada na construção de sua identidade. Ao tempo em que se diferenciam umas das outras, elas podem e devem se complementar, em desenhos públicos significativos e ousados

Paulo Freire afirma a educação como escolha e ato político, a ética do respeito aos sujeitos - estudantes, professores e funcionários - e a estética: a produção dos projetos que essa experiência ética cria são desenhos coletivos e únicos. As escolas devem ter assegurada a boniteza da possibilidade aberta ao ser humano, que vive a realização plena do tempo histórico, ou seja, que faz o resgate do passado no presente para a superação efetiva das amarras que o presente impõe em novas configurações de futuro. 
São concepções freireanas que conscientizam a escola e a Universidade de sua incompletude, fazendo desta constatação o motor de sua transformação - do avaliar e do planejar - a escola e a universidade como autoras de um projeto político pedagógico significativo e mobilizador da comunidade.

A relação dialógica e democrática dá sentido às ações formativas a todos que se colocam, momentaneamente, como educadores ou educandos (a universidade que aprende com a escola para poder ensinar aos licenciandos, que vindos da prática dos estágios também cumprem esse papel), pois:

Na dialogicidade, na problematização, educador-educando e educando-educador vão ambos desenvolvendo uma postura crítica da qual resulta a percepção de que este conjunto de saber se encontra em interação. Saber que reflete o mundo e os homens, no mundo e com ele, explicando o mundo, mas sobretudo, tendo de justificar-se na sua transformação (FREIRE, 1983, p. 44-45)

Propõe-se, ao mesmo tempo e como exercício democrático, "uma epistemologia da escuta em oposição à epistemologia do olhar em consequência das características das práticas educativas" (BERGER, 2009).

Escola não é prédio! Ainda que este tenha muita importância em sua configuração, a escola e a universidade são instituições mediadas pelo conhecimento que aproxima gerações. Devem ser permanentemente desafiadas a responder aos desafios de natureza social e histórica, em determinado tempo e lugar.

\section{CONSIDERAÇÕES FINAIS}

Atualmente, estão em debate duas propostas de formação: uma com base em modelos e outra como processo participativo e democrático em construção. A primeira tem como características: regras e fluxos de formação pré-estabelecidos; definição rígida de indicadores e de processos avaliativos; material impresso e outros - tipo kit definidos; preocupação acentuada com a forma/imagem e a comunicação de resultados e proposta de replicação do modelo.

São seus paradigmas: o indivíduo isolado e sua empregabilidade; os referenciais econômicos e de mercado - a educação como produção de um produto/mercadoria; a concordância com os referenciais dos Organismos Internacionais, especialmente, do Banco Mundial e da OCDE (PIZA); a forte crítica às ações públicas estatais de formação e a cobrança da produtividade das universidades públicas; a defesa de uma linha de privatização do ensino superior; os programas de formação voltados para práticas e cumprimento de tarefas, envolvendo tecnologias de informação; as propostas de formação a distância, 
tendo como exemplo as Universidades Virtuais, difundidas pelo Banco Mundial/ IFC; a defesa da localização de Centros Avançados difusores de conhecimento e de formação em países do primeiro mundo.

A segunda pretende a emancipação dos sujeitos individuais e coletivos: exige a indignação frente às questões sociais, propõe mudança; define objetivos de percurso: o caminho a ser seguido depende de onde se quer chegar (CARROLL, 2009) ; considera a experiência social dos indivíduos - fundamental a participação e a gestão democrática das decisões; baseia-se num método que permita a apreensão criteriosa, criativa e curiosa; tem referenciais de criação estéticos (a beleza importa) e éticos (formadores e formandos são sujeitos que se encontram no diálogo sobre o mundo), tem expectativa e responsabilidades como contrafaces da participação; cobra a promessa de igualdade aos governantes e porta uma utopia; exige pesquisa permanente dos formadores - aprender-ensinarpesquisar, pratica uma avaliação qualitativa - indicadores construídos mediante a negociação dos sujeitos sobre a qualidade que se quer durante e no final/reinício da formação; comporta o risco - "viver é perigoso" (Guimarães Rosa) e permite reaplicação criativa .

Longe de paradigmas estáticos e rigidamente definidos, considera a história e a transformação, tendo como referenciais: o conceito do Estado como campo de tensão; a defesa de políticas públicas de qualidade; a consciência da luta permanente por direitos tem implicação tributária (fundo público) e no funcionamento jurídico do Estado; considera que o Mercado e a Economia devem se alinhar a propostas de emancipação social - apresentando postura crítica frente ao Mercado e Economia globalizados; afirma a soberania dos países, o direito à diferença e defende a qualidade de vida dos povos e de sua formação.

Os três relatos apresentados neste artigo filiam-se à segunda proposta. O contraponto trazido a esta conclusão entre estas duas propostas, que disputam lugar na cabeça e na prática dos educadores-educandos, visa destacar a importância dessas formações que se amparam nas afirmações desta opção. A luta dos movimentos sociais percorre a história do país, mas nem sempre é desvelada em sua força propulsora. Paulo Freire entra na história da luta das forças populares por direitos nos anos de 1950. Sem dúvida, sua presença até hoje revigora práticas democráticas dos que nela se fazem presentes.

A dominação, opressão e desigualdade no Brasil vêm de longa data, mas a luta contra elas também é antiga e persistente - as pequenas chamas resistem em não se apagar.

A proposta freireana é forte porque, portadora de utopia, afirma, de repente, que é possível ter esperança na forma democrática de se colocar no mundo. 


\section{REFERÊNCIAS}

ARDOINO, Jacques; BERGER, Guy. L'évaluation comme interprétation. In POUR, no 107, 1986, p. 120-27.

BERGER, Guy. A investigação em Educação - Modelos socioepistemológicos e inserção institucional. Educaşão, Sociedade \& Culturas, no 28, 2009, 175-192.

BEGNAMI, João Batista. Pedagogia da Alternância em movimento. In: Mônica Castagna Molina, Maria de Fátima Almeida Martins [orgs.]. Formação de formadores: reflexões sobre as experiências da licenciatura em educação do campo no Brasil. 1. ed. Belo Horizonte, MG: Autêntica Editora, 2019.

BRANDÃO, Carlos Rodrigues. CULTURA (Movimentos de cultura popular). In: STRECK, Danilo R.; REDIN, Euclides; ZITKOSKI, Jaime José (Org.). Dicionário Paulo Freire. 2 ed., rev. amp. 1. reimp. Belo Horizonte: Autêntica Editora, 2010.

BOGO, Ademar. Mística. In: CALDART et al. (Org.) Dicionário da Educação do Campo. Rio de Janeiro, São Paulo: Escola Politécnica de Saúde Joaquim Venâncio, Expressão Popular, 2012.

CARROLL, Lewis. Aventuras de Alice no país das maravilhas; Através do espelho e o que Alice encontrou por lá. (Trad. por Maria Luiza Xavier de Almeida Borges). Rio de Janeiro: Zahar, 2009.

FREIRE, Paulo. Extensão ou Comunicação? Rio de Janeiro: Paz e Terra, 1983. Pedagogia do Oprimido. 11. ed. Rio de Janeiro: Paz e Terra, 1987.

. A Educação na Cidade. São Paulo: Cortez, 1994.

Política e Educação: ensaios. 5. ed - São Paulo, Cortez, 2001

Alfabetização e Cidadania. Texto publicado na Revista Educação Municipal, ano 1, nº 1, Junho/1988 - UNDIME - Ação Direta - Cortez Editora - São Paulo, 1988. 
Pedagogia da Autonomia: saberes necessários à prática educativa. 13. ed. São Paulo: Paz e Terra, 1999.

FREITAS, Luiz Carlos de. A Reforma Empresarial da Educação - nova direita, velhas ideias. 1 ed. São Paulo: Expressão Popular, 2018.

FONEC. FÓRUM NACIONAL DA EDUCAÇÃO DO CAMPO. Notas para análise do momento atual da Educação do Campo. In: SEMINÁRIO NACIONAL, Brasília, 2012.

GADOTTI, Moacir. Realidade. In: STRECK, Danilo R.; REDIN, Euclides; ZITKOSKI, Jaime José (Org.). Dicionário Paulo Freire. 2 ed., rev. amp. 1. reimp. Belo Horizonte: Autentica Editora, 2010.

MARTINS, Izabel Cristina; JEZINE, Edineide. Percepção de educação popular na expansão da Educação Superior do Campo. In: SOUSA, José Vieira de; BOTELHO, Arlete de Freitas; GRIBOSKI, Claudia Maffini (Orgs.). Produção do conhecimento e educação do campo na expansão da educação superior. Anápolis-GO: Ed. UEG, 2018.

MOVA-SP (Movimento de Alfabetização de Jovens e Adultos da Cidade de São Paulo). São Paulo. MOVA-SP, Caderno n ${ }^{\circ}$, Secretaria Municipal de Educação, outubro de 1989.

. (Movimento de Alfabetização de Jovens e Adultos da Cidade de São Paulo). São Paulo. MOVA-SP, Construindo o Ciclo Ensino Fundamental I, setembro de 1992.

MENDES, Geisa do S. C. V. et al . Autoavaliação como estratégia de resistência à avaliação externa ranqueadora. Educ. Pesqui., São Paulo, v. 41, n. spe, p. 1283 1298, dez. 2015.

TERRASÊCA, Manuela. Questões Aprofundadas de Avaliação em Educação - Relatório da Disciplina. Porto: FPCE-UP, 2006.

SILVA, Maria do Socorro. Da raiz à flor: produção pedagógica dos movimentos sociais e a escola do campo. In: Molina, Mônica Castagna (Org.). Educação do Campo e Pesquisa: questões para reflexão. - Brasília: Ministério do Desenvolvimento Agrário, 2006. 


\section{Sonia Maria Portella Kruppa}

Doutora em Educação pela Universidade de São Paulo. Trabalhou com Paulo Freire na Secretaria Municipal de Educação de São Paulo (1989-1992) e com Paul Singer na Secretaria Nacional de Economia Solidária do Ministério do Trabalho e Emprego (SENAES-MTE 2003-2005). Professora do Departamento de Administração e Economia da Educação da Faculdade de Educação da Universidade de São Paulo e coordenadora do Núcleo de Avaliação Institucional (NAI-FEUSP), São Paulo, SP, Brasil. E-mail: skruppa@usp.br

\section{Silvia Andrade da Silva Telles}

Mestre em Educação pelo Programa de Pós-Graduação de Educação da Faculdade de Educação da Universidade Federal Fluminense. Professora do Ensino Superior aposentada - Universidade Nove de Julho - UNINOVE, São Paulo, SP, Brasil. E-mail: sastelles@gmail.com

\section{Aline Aparecida Angelo}

Graduada em Pedagogia pela Universidade Federal de Viçosa, Mestre em Educação, pela Universidade Federal de São João del-Rei e Doutora em Educação pela Universidade de São Paulo (USP). Professora no Curso de Licenciatura em Educação do Campo da Universidade Federal do Maranhão. Bacabal, MA, Brasil. E-mail: aline.angelo@ufma.br 